\title{
Skúlason's Viren-Schutzgebote
}

\section{Fridrik Skúlason}

Nie sollte man eine Diskette im Laufwerk liegen lassen, wenn der Computer gebootet wird. Wenn das passiert und die Meldung "Not a system disk" auf den Bildschirm angezeigt wird, könnte bereits ein Virus installiert worden sein. Dann ist es ratsam, den Computer aus- und wieder einzuschalten. Wichtig ist, daß es nicht genügt, einen Warmstart (Ctrl-Alt-Del) auszuführen. Viele Viren 'überleben' das.

Nie sollten Sie einen Computer von Diskette booten, wenn das nicht dringend erforderlich ist. Boot-Viren können auf die Festplatte übertragen werden und dann jede Diskette infizieren, die später eingelegt wird.

Nie sollten Sie Dateien auf Disketten, die auch Programme beinhalten, von einem Computer zu einem anderen übertragen.

$\square$ Auf einem Computer, der nicht mit einer Festplatte ausgestattet ist und von Diskette gebootet werden muß, sollte man immer dieselbe Diskette benutzen und die sollte schreibgeschützt sein.

$\square$ Wichtig ist es, ein Backup von allen Programmen und Dateien zu besitzen. Backups zu haben, ist nicht nur eine Sicherheitsmaßnahme gegen Viren, sondern auch gegen eventuelle Hardwarestörungen und - last but not least - gegen eigene Fehler.

Stellen Sie alle Disketten, auf die Sie nicht kopieren müssen, auf Schreibschutz. Das gilt auch für Programmdisketten. Machen Sie eine Kopie davon und bewahren Sie das Orginal an einem sicheren Ort auf. Auf diese Weise verfügen Sie immer über ein nicht infiziertes Exemplar von Ihren Programmen, falls Ihr Computer von Viren befallen wird.

Seien Sie vorsichtig im Umgang mit allen Programmen, die Sie bekommen, sei das ein Spiel von den Philippinen oder ein Tabellenkalkulationsprogramm. Sind Disketten nicht in ihrer ursprünglichen Packung direkt vom Hersteller, kann es durchaus sein, daß sie infiziert sind. Fragen Sie zumindest nach, was derjenige, der Ihnen das Programm gegeben hat, für Sicherheitsmaßnahmen unternommen hat. Für den Fall, daß er allgemein keine Sicherheitsmaßnahmen ergreift, versuchen Sie, das Programm von anderswo zu bekommen.

Versuchen Sie, Programme immer vom Autor oder dessen Direkt-Händler zu bekommen. Je mehr Leute dazwischen geschaltet sind, desto höher ist das Risiko der Infektion. Ohne angemessene Werkzeuge ist es sehr schwer herauszufinden, ob ein Programm infiziert ist oder nicht.

$\square$ Immer wenn Sie neue Software bekommen, sollten Sie vor dem ersten Einsatz prüfen, ob das Programm befallen ist. Verwenden Sie immer aktuelle Antiviren-Programme. Es ist sogar ratsam, mit mehreren Anti-Viren-Programmen von mehreren Herstellern zu arbeiten.

$\square$ Gewöhnen Sie sich daran, Disketten sofort aus Laufwerken zu entfernen, wenn Sie sie nicht mehr benötigen.

$\square$ Bleiben Sie aufmerksam für alle Änderungen und schauen sie nach, ob irgendwas Ungewöhnliches passiert. Achten Sie u.a. auf folgendes:

- Dauert es länger als gewohnt, Programme zu laden?

- Erscheinen Fehlermeldungen bei Abläufen, die früher reibungslos durchgeführt wurden?

- Leuchtet die Beleuchtung von Laufwerk oder Festplatte, wenn kein Arbeitsablauf aktiv sein sollte?

- Scheint der Speicherplatz des Computers plötzlich geringer zu sein?

- Verschwinden Verzeichnisse ohne erklärbaren Grund?

- Wird freier Platz auf der Festplatte plötzlich geringer? 